\title{
Generalized Tetanus in an 8-Years-Old Boy: A Case Report
}

\author{
Katharina Yosephin Lakonawa*, I Made Gede Dwi Lingga Utama, I Wayan Gustawan \\ Department of Child Health, Medical Faculty of Udayana University, Sanglah General Hospital, Denpasar, Bali, Indonesia
}

\author{
Email address: \\ elfienlakonawa@gmail.com (K. Y. Lakonawa),dwi_lingga09@yahoo.com (I M. G. D. L. Utama), \\ iwayangustawan@gmail.com (I W. Gustawan) \\ ${ }^{*}$ Corresponding author
}

\section{To cite this article:}

Katharina Yosephin Lakonawa, I Made Gede Dwi Lingga Utama, I Wayan Gustawan. Generalized Tetanus in an 8-Years-Old Boy: A Case Report. American Journal of Pediatrics. Vol. 6, No. 4, 2020, pp. 428-432. doi: 10.11648/j.ajp.20200604.16

Received: September 21, 2020; Accepted: October 7, 2020; Published: October 23, 2020

\begin{abstract}
Nowadays tetanus is a rare disease in developed countries due to the success of immunization, but children who were not immunized are still at risk. Awareness of early clinical symptoms of tetanus is crucial since the diagnosis is based on clinical symptoms. Severe tetanus can occur and lead to sequelae if there was no timely diagnosis and proper treatment. This case report aimed to emphasize the importance of recognizing early symptoms of tetanus and immunization. An 8 year old boy complained stiffness all over his body since 4 days before admission to hospital. Stiffness was started with pain on his back and stomach since 7 days before admitted, 3 days later his neck and back became stiff and got worsen until his mouth became stiff too. His left toe was pricked by a plant thorn about 3-4 weeks before admission. Physical examination showed risus sardonicus, trismus, stiff hands and opisthotonus. He didn't get complete immunizations. He was admitted in Pediatric Intensive Care Unit (PICU) with Human Immunoglobulin, metronidazole, and diazepam. He was treated for 14 days and given Td vaccine before discharged. He underwent physiotherapy in medical rehabilitation department for 1 month because of persisting stiffness in his legs and arms. The diagnosis of tetanus was made based on clinical findings. There was no laboratory test to confirm it. Without timely diagnosis and proper treatment, severe tetanus can be fatal causing sequelae. Tetanus treatment follows several principles such as initial stabilization, maintainance of airway, prevent absorption of tetanospasmin, eradicating organism and supportive therapy. Management of tetanus takes a long time because the irreversible bound of toxin to tissues. It takes 4-6 weeks for the growth of new nerve terminal which is required in recovery period. So it is very important to recognize the symptoms of tetanus and treat it immediately to prevent more toxin bind to neuron.
\end{abstract}

Keywords: Tetanus, Diagnosis, Incompleted Immunization, Management, Recovery Time

\section{Introduction}

Tetanus can be a serious and life-threatening infectious disease with fatal outcome if not detected and treated at early stage. Historically, tetanus has been a major cause of death worldwide, largely due to inadequate vaccination and poor wound prophylaxis. Now, the number of cases has decreased after the implementation of universal vaccination [1].

However infants whom are not immunized due to religious objection or philosophical reason are still at risk. The low incidence of tetanus in developed countries has decreased vigilance of this disease. This raises concern, as the prodromal stadium of generalized tetanus infection might not show paroxysmal muscle spasms. Tetanus can rapidly progress into life-threatening muscle spasms accompanied by respiratory insufficiency and/or autonomic dysfunction. This emphasizes the need for early diagnosis and treatment [2].

The incidence of tetanus depends on the population that is unvaccinated, the level of biological pollution of farm / agriculture environment and the presence of injuries on skin or mucosa. Tetanus in children is present worldwide, especially in high risk areas with low DPT immunization coverage. The incidence is higher in male, due to differences of physical activity. Tetanus does not spread from human to human [3]. World Health Organization (WHO) stated the incidence of tetanus worldwide is around $700,000-1,000,000$ cases per year with mortality rates ranging from $6 \%$ to $60 \%$ [4].

However over the past 20 years, the incidence of tetanus has decreased with increasing immunization coverage. 
Tetanus neonatorum causes $50 \%$ of perinatal deaths and accounts for $20 \%$ of infant deaths. The incidence about $6-7$ per 100 live births in urban areas and 11-23 per 100 births live in rural areas. While the incidence of tetanus in children in hospital about 7-40 cases anually, 50\% occurs in groups of $5-9$ years old, $30 \%$ groups $1-4$ years old, $18 \%$ groups $>10$ years old and the rest in infants $<12$ months old $[5,6]$.

Tetanus still become public health problem in Indonesia even though the incidence decreases in line with implementation of immunization program against tetanus [7]. In Indonesia, 3363 cases of tetanus per years was reported between 1990 and 1993 with case fatality rate (CFR) ranging 9.9 to $15.3 \%$. In RSCM Jakarta, the incidence of tetanus in children during 2003 were 10 cases with CFR 20\% and in 2007 there were 18 cases with CFR being 0\% [3].

Tetanus is vaccine-preventable disease that is infectious but not contagious [8]. The rarity of tetanus making clinicians unexperience in handling this case. Awareness of early clinical symptoms of tetanus is crucial because the diagnosis of tetanus is based on clinical symptoms. Severe tetanus can occur and lead to sequelae if there was no timely diagnosis and proper treatment [9].

Hereby we report a case of generalized tetanus in an 8 years old boy whom had incomplete vaccination. The purpose of this report is to describe the clinical cases of pediatric patient with generalized tetanus and strengthen the importance of vaccination and early diagnosis.

\section{Case}

An 8 years old boy was referred from $\mathrm{N}$ hospital with chief complaint stiffness all over his body since 4 days before admission. Stiffness was started with pain on his back and stomach since 7 days before admission, but the patient still could perform his daily activity, 3 days later the patient's neck and back became stiff then he was brought by his parents to $\mathrm{N}$ hospital. He was given intravenous fluid D5 $1 / 2$ saline, paracetamol, ceftriaxone, omeprazole and probiotic but the stiffness was getting worse until the patient's mouth became stiff too. Moreover he easily get startled especially by loud voice, the stiffness was getting worse and was followed by pain all over his body.

In the beginning, about 3-4 weeks before admission, the patient's left toe's thumb was pricked by plant's thorn when he was playing in front of his house. The wound was cleaned by water without any additional medication was given by his parents. During illness, the patient only able to drink water and milk. Patient still able to defecate and urinate. Fever, shortness of breath, seizure, loss of consciousness were denied by patient. History of pus coming out of ears, injury due to knife and wound from animal's bite were denied. Since born the patient only got oral polio immunization 1 time because of his parents' religious objection.

Physical examination showed the patient appeared severely ill, good consciousness, blood pressure 100/70 $\mathrm{mmHg}$, heart rate 110 beats/minute, respiratory rate 24 times/minute with temperatures ranged between $37^{\circ} \mathrm{C}$, oxygen saturation $98 \%$ in room air, pain scale 3, pupils were isocor. There were risus sardonicus, trismus, stiffness of extremities (figure 1). A stab wound was found with size less than $0.1 \times 0.1 \mathrm{~cm}$, no pus, no necrotic tissue were found. There was no sign of lateralization. Nutritional status based on waterlow was well nourished.

The patient was then diagnosed with tetanus grade III due to wound on left toe. The patient was treated in Pediatric Intensive Care Unit (PICU) with minimal light and sound. The patient was treated with Human Immunoglobulin (Tetagam) 3000-6000 international unit (single dose intramuscular) $\sim 3000$ international unit, metronidazole 15 $\mathrm{mg} / \mathrm{kg} / \mathrm{day} \sim 400 \mathrm{mg}$ intravenously then followed by maintenance dose $30 \mathrm{mg} / \mathrm{kg} / \mathrm{day} \sim 190 \mathrm{mg}$ every 6 hours for 10 days, diazepam $0,3 \mathrm{mg} / \mathrm{kg} /$ times $\sim 7.5 \mathrm{mg}$ every 4 hours intravenously, oxygen 4 liter per minute, enteral feeding via nasogastric tube. On the $4^{\text {th }}$ day of treatment, stiffness on his body decreased, thus the dosage of diazepam was decreased into $7.5 \mathrm{mg}$ every 6 hours. Wound care and gentamycin ointment were also given. On the $7^{\text {th }}$ to $8^{\text {th }}$ days of treatment, the dose of diazepam was reduced by $20 \%$ from the previous dose to $6 \mathrm{mg}$ every 6 hours. On the $9^{\text {th }}$ to $10^{\text {th }}$ days of treatment, the dose of diazepam was reduced by $20 \%$ again to $5 \mathrm{mg}$ every 6 hours. On the $11^{\text {th }}$ day of treatment, the administration of diazepam was changed to oral, the patient was able to eat soft food, but his legs and arms were still stiff, so the patient was consulted to department of medical rehabilitation. On $12^{\text {th }}$ to $13^{\text {th }}$ day of treatment, the dose of diazepam was reduced by $20 \%$ again to $4 \mathrm{mg}$ every 6 hours. On the $13^{\text {th }}$ day of treatment, the patient's extremities were still stiff however he could walk with assistance. On the $14^{\text {th }}$ days of treatment, the patient was given Td vaccine and discharged with scheduled control to department of medical rehabilitation for physiotherapy. The patient underwent physiotherapy for a month and recovered without sequelae.

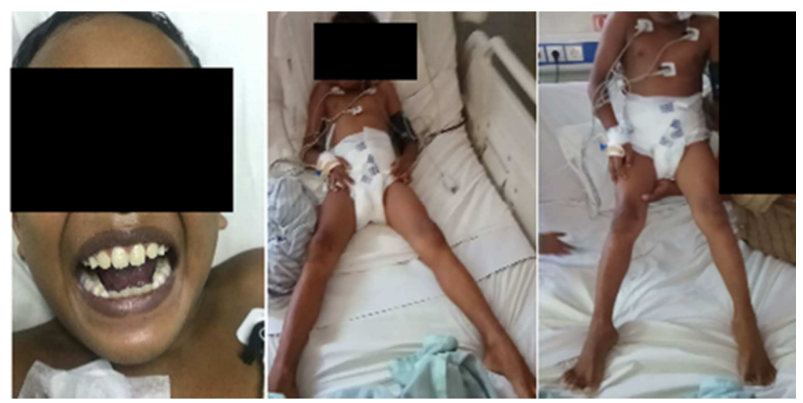

Figure 1. Patient's clinical manifestation while admitted in PICU.

\section{Discussion}

Tetanus is a disease from specific toxin produced at site of injury by Clostridium tetani, which is found in soil and feces [3]. Tetanus is a neurotoxin-mediated disease characterized by progressive spastic paralysis of multiple muscle groups. The neurotoxin (tetanospasmin) disrupts neurotransmitter release in inhibitory neurons, leading to rigidity and spasms of peripheral muscle. Tetanospasmin is produced by obligate anaerobic Clostridium tetani, which its spores are 
ubiquitously distributed in our environment. This causes inevitable risk of tetanus infection after wound contamination. Muscle rigidity and spasms are the clinical hallmarks of generalized tetanus including trismus (lockjaw) and opisthotonus [2].

Almost all reported cases of tetanus are suffered by either vaccinated or whom completed a primary series but had not got booster in the preceding 10 years [8]. Complete basic immunization coverage in Indonesia in five years (20132017) reached above $85 \%$, but it still has not reached the strategic plan by Ministry of Health. In 2017 complete basic immunization in Indonesia was reported $91.12 \%$. This figure was slightly below the target of strategic plan in 2017 at $92 \%$. Percentage of children aged 12-24 months who received booster of DPT-HB-Hib immunization in 2017 was $63.5 \%$. This coverage has reached the 2017 target of $45 \%$ and has approached the 2019 target of $70 \%$. DT immunization in grade 1 elementary school children was $95.4 \%$ and $\mathrm{Td}$ immunization in grade 2 elementary school children was $97.49 \%$ [9].

Tetanus has become rare due to effective vaccination program. Due to its rarity, many physicians do not consider the diagnosis until the manifestations become overt causing delay in diagnosis. Without timely diagnosis and proper treatment, tetanus could be fatal and causing sequelae $[1,2]$. In this case, the patient had suffered stiffness on his neck and back, but was not suspected of suffering tetanus until stiffness got worsen and the trismus appears, then the patient was referred to Sanglah hospital.

The diagnosis of tetanus was made based on clinical findings. There is no laboratory test to confirm it. The wound cultures are often negative with yield of C. tetani only in $30 \%$. The serologic testing for antitetanus antibodies is usually done to look for inadequate vaccination which gives low or negative level but tetanus can occur even in the presence of protective levels of antibodies. Serology can be used as supportive test if it is negative or poorly positive, however it cannot be relied on to rule out the disease if it is strongly positive in highly suspicious cases [2].

The World Health Organization (WHO) defined neonatal tetanus as the loss of suck and cry between 3 and 28 days after birth, along with the development of rigidity or spasms in an infant with normal suck and cry in the first 2 days after birth. Infants with neonatal tetanus will develop irritability, weakness, stiffness, opisthotonus, which eventually leads to death [11]. The WHO define non-neonatal tetanus as trismus, risus sardonicus, or painful muscular contractions along with history of wound or injury [1]. The most frequent symptom noted was stiffness of neck or upper back. This symptom occurred in 15 of the 22 patients. It often occurs before there were any symptoms on jaw [10]. In this case, stiffness starts from the neck and back then extends throughout the body. Moreover physical examination showed risus sardonicus, trismus of his mouth, stiff hands and opisthotonus.

Clinically tetanus is classified as general, cephalic, local, or neonatal tetanus. In general tetanus, clinical symptoms that often appear include muscle weakness, stiffness throughout the body and autonomic instability. The incubation period from initial inoculation to the onset of symptoms varies from few hours to more than 1 month, in which $80 \%$ of cases of develop symptoms after 2 weeks of inoculation. Seventyfive percent of patients experience stiffness in masseter muscles which is known as trismus or "lock jaws". Other symptoms that may arise include dysphagia, pain and stiffness of shoulders and back muscles. Another finding is sardonic risus (grimace caused by facial muscle contraction), stiffness of abdomen, and opistotonus (curved back due to back muscle tonic contraction). Cephalic tetanus is a rare manifestation of tetanus which is often associated with head injury or chronic media otitis. Patients usually complaint trismus and have cranial nerve paralysis. Localized tetanus is characterized by muscle weakness that occurs around the wound. In severe case patient can develop generalized tetanus or chronic muscle function abnormalities. Localized tetanus is very rare, and usually has good prognosis [11].

Tetanus can be divided into 4 degrees. First degree (mild tetanus) is characterized by mild to moderate trismus, stiffness of neck, opistotonus and abdominal board, without dysphagia, seizures or respiratory disturbances. Second degree (moderate tetanus) is characterized by moderate trismus, stiffness, seizures due to stimulation, tachypnea, mild dysphagia. Third degree (severe tetanus) is characterized by severe trismus, spastic muscles, spontaneous seizures, tachypnea, tachycardia, apneic attacks, severe dysphagia, increase autonomic system activity. Fourth degree (terminal stage) that is symptoms of third degree added with severe autonomic disorders [8]. In this case, based on history taking and physical examination, we concluded this patient suffered third degree of generalized tetanus.

Management of tetanus takes a long time, weeks to months. Tetanus treatment requires intensive care, depends on the severity and complications. Tetanus treatment follows several principles such as initial stabilization and maintaining patency of airway, preventing absorption of tetanospasmin, eradicating organism and supportive therapy [11, 12]. Initial stabilization and maintaining patency of airway can be done by making the room dark and quiet to minimize stimulation that induce muscle spasm. Other complications that can occur such as spasm of larynx, thus intubation and ventilators are usually needed in moderate and severe cases [13].

Prevention of tetanospamine absorption can be done by injection of human tetanus immunoglobulin (HTIG) which directly neutralizes free tetanospasmin. Centers for Disease Control and Prevention (CDC) recommended HTIG 250 IU should be given as prophylactic in high-risk patients, while for therapeutic dose should be 3000-6000 IU. The HTIG should be given as soon as the airway is stable, which is injected intramuscular in deltoid muscle, or opposite to the site of tetanus toxoid injection. If there is a wound that triggers tetanus, HTIG shall be given before debridement because free tetanospasmin can be released during manipulation of action. The half-life of HTIG is approximately 28 days so repeated doses are not needed. HTIG does not pass through blood brain barrier, so it cant be 
used to fight toxins that passed through CNS [14]. Administration of human antitetanus immunoglobulin (HTIG) has been established as treatment of tetanus. Since the damage caused by tetanospasmin that entered nervous system is irreversible, many literatures emphasized it to neutralize the circulating toxin before it enters the nervous system. This patient was given intravenous immunoglobulin. Kabura et al. stated that intrathecal administration of serum tetanus (ATS) or human tetanus immunoglobulin (TIG) was better than intramuscular administration of tetanus treatment [15]. Thus we administered intravenous immunoglobulin based on the patient's clinical condition.

Some antibiotics such as penicillin, cephalosporin, macrolide, tetracycline, imipenem and metronidazole were said able to fight $\mathrm{C}$. tetani by invitro. Based on research conducted at University of Indonesia, Jakarta in 1985, it was stated that metronidazole was more superior than penicillin, because it could reduce mortality in tetanus patients. Metronidazole was effective in reducing the amount of vegetative $C$. tetani bacteria. As second-line procaine penicillin could be given 50.000-100.000 U/kgBW/day for 710 days, if there was hypersensitivity to penicillin, tetracycline could be given $50 \mathrm{mg} / \mathrm{kgBW} /$ day (for children over 8 years) [16]. In this case, the patient received metronidazole $15 \mathrm{mg} / \mathrm{kgBW} /$ day $\sim 400 \mathrm{mg}$ intravenously then followed by maintenance dose $30 \mathrm{mg} / \mathrm{kgBW} /$ day $\sim 190$ mg every 6 hours for 10 days.

Supportive therapy could also be given to patients with tetanus in the form of neuromuscular block and ventilator support. Benzodiazepines can be used as sedation and muscle relaxation. Another muscle relaxant that can be used were baclofen or dantrolene. Some studies also recommend vecuronium because less side effect on heart and CNS. Diazepam, lorazepam, and midazolam muscle relaxants also available in parenteral preparations that can be given continuously. Diazepam effectively overcomes spasm and hypertonicity without suppressing effect on cortical. The recommended diazepam dose was $0.1-0.3 \mathrm{mg} / \mathrm{kgBW} /$ times with 2-4 hour intervals according to clinical symptoms or $8 \mathrm{mg} / \mathrm{kgBW} /$ day given orally in $2-3 \mathrm{mg}$ doses every 3 hours for patient aged $<2$ years old. If anticonvulsant therapy has provided the expected clinical response, the dose is maintained for 3-5 days. Furthermore, dose reduction is done in stages (ranging from $20 \%$ of the dose every 2 days) [17]. In this case, the patient received diazepam $0,3 \mathrm{mg} / \mathrm{kg} / \mathrm{times} \sim$ $7.5 \mathrm{mg}$ every 4 hours for 3 days and then the dosage was tapered down $20 \%$ every 2 days.

Some of the risk factors that can make someone suffer from tetanus include poor wound treatment, inability to take action, piercing sharp objects contaminated with $\mathrm{C}$. tetani and incomplete immunization. Immunization is given so that children become more immune to germs. A child's body will form antibodies after being given an antigen. One of the important immunizations for child is DPT (diphtheria, pertussis, and tetanus) which can prevent children from developing tetanus. Protective levels of tetanus antitoxin in the body $(\geq 0.01 \mathrm{IU} / \mathrm{ml})$ is expected by periodic immunization [18]. In this case, the basic immunization of the patient was incomplete. Patients only got oral polio immunization one time. His left toe's thumb was pricked by the plant's thorn which was also a risk factor for tetanus. The wound caused $\mathrm{C}$. tetani easily entered the body, developed spores into vegetative forms followed by released of tetanospamine toxin which caused tetanus symptoms.

Immunization with tetanus toxoid is effective for prevention with low failure rate. There are two types of tetanus toxoid available; adsorbed (precipitated aluminum salt) toxoid and fluid toxoid. The antitoxin protection after complete administration of tetanus toxoid showed clinical benefits up to $100 \%$. Tetanus cases are rare in people who have been fully immunized within 10 years after the last dose In some people, immunity can occur for lifetime or in most people have minimal antitoxin levels after 10 years. As a result, routine booster immunization is needed every 10 years. Therefore, the role of prevention by immunization is very important. It was reported in the United States, tetanus only occur in children who are not immunized because parents refuse to vaccinate [19].

Patients who have clean and small wounds with history of immunization less than 3 times or unclear history of immunization need to get $\mathrm{Td}$ or TdaP vaccines, but if the history of immunization is more than 3 times then there is no need to get vaccines or TIG. If the patient comes with wounds contaminated by feces / stool, soil, and saliva (puncture, avulsion, gunshot wounds, collisions, burns and frostbite) with history of immunization less than 3 times or unclear history of immunization that is necessary to get Td or TdaP vaccines and TIG, but if the history of immunization was more than 3 times then there is no need to get vaccines or TIG [20]. In this case, the patient received $\mathrm{Td}$ vaccine because the TdaP vaccine was not available.

Antitoxin administration is done as soon as possible after the diagnosis of tetanus is confirmed. HTIG can only eliminate tetanus toxins that have not bind to nerve endings. A study stated that recovery in children with tetanus after treated based on standard therapy was one month [21]. In this case, the patient was able to walk but still experienced stiffness of his legs and arms while discharged so he still has to follow physiotherapy for a month. This is caused by toxin that was bound to neuron tissues. Recovery requires the growth of new nerve terminal which takes four to six weeks [8].

There was no literature about the role of physiotherapy in tetanus patients. However, there was no evidence that physiotherapy could cause adverse effects in these patients. Therefore, physiotherapy can performed to prevent joint deformities and muscle shortening [17].

\section{Conclusion}

Diagnosis of tetanus is made based on clinical findings, history taking and physical examination. Furthermore complete immunization history is the basic key for diagnosis. There is no laboratory test to confirm tetanus. Timely 
diagnosis and proper treatment is crucial to prevent severe tetanus which is fatal and can cause sequelae. This report emphasized the need for early diagnosis and treatment based on clinical findings, and highlighted the importance of immunization.

\section{References}

[1] Thwaites CL, Farrar JJ. Preventing and treating tetanus. The challenge continues in the face of neglect and lack of research. BMJ. 2003; 326 (7381): 117-8.

[2] Cherry JD, Harrison GJ, Kaplan SL, Hotez PJ, Steinbach WJ. Feigin and Cherry's Textbook of Pediatric Infectious Diseases. 7th ed. Philadelphia: Elsevier; 2014.

[3] Sumarmo SPS, Garna H, Hadinegoro SR, Satari HI. Buku Ajar Infeksi dan Penyakit Tropis: Tetanus. Edisi 2. Jakarta: IDAI; 2008.

[4] Mandell G, Bennett J, Dolin R. Mandell, Douglas, and Bennett's Principles and Practice of Infectious Diseases. 7th ed. Philadelphia: Churchill Livingstone; 2000: 2537-43.

[5] Roper MH, Vandelaer JH, Gasse FL. Maternal and neonatal tetanus. Lancet. 2007; 370: 1947-59.

[6] Centers for Disease Control and Prevention (CDC). Tetanus surveillance-United States, 2001-2008 [cited 2020 Jan 12]. Available https://www.cdc.gov/mmwr/preview/mmwrhtml.

[7] Lestar W, Widyaningrum D, Sumarno, Siburian F. Immunnity to diptheriae and tetanus of primary school dropout children in North Jakarta Municipality. Buletin Penelitian Kesehatan. 2002; 202: 152-6.

[8] Cook TM, Protheroe RT, Handel JM. Tetanus: A review of the literature. Br J Anaesth. 2001; 87: 477-87.

[9] Kementrian Kesehatan Republik Indonesia. [Profile of Indonesia Health 2017] Profil Kesehatan Indonesia tahun 2017. [cited 2020 Jan 12]. Available from: https://www.kemkes.go.id/resources/pusdatin/profilkesehatan-indonesia-tahun-2017.

[10] Edmund M, Fountain MD. The early symptoms of tetanus with a review of 22 cases. Canad. M. A. J. 1951; 64: 58-60.
[11] Ernest ME, Michael EK, Michael F, Markos NM. Tetanus: Pathophysiology and management. Ann Pharmacother. 1997; 31: 1507-13.

[12] Thwaites CL, Loan HT. Eradication of tetanus. British Medical Bulletin. 2015; 116: 69-77.

[13] Hsu SS, Georgina G. Tetanus in the emergency department: A current review. The Journal of Emergency Medicine. 2001; 20: 357-65.

[14] Rodrigo C, Deepika F, Senaka R. Pharmacological management of tetanus: Evidence-based review. Critical care. 2014; 18: 1-10.

[15] Kabura L, Ilibagiza D, Menten J, Van den Ende J. Intrathecal vs intramuscular administration of human antitetanus immunoglobulin or equine tetanus antitoxin in the treatment of tetanus: A meta-analysis. Tropical Medicine and International Health. 2006; 2: 1075-81.

[16] Ahmadsyah I, Agil S. Treatment of tetanus: An open study to compare the efficacy of procaine penicillin and metronidazole. British Medical Journal. 1985; 291: 648-50.

[17] Lisboa T, Li Ho Y, Henriques Filho GT, Brauner JS, Valiatti dos Santos JL, Verdeal JC, Machado FR. Guidelines for the management of accidental tetanus in adult patients. Rev Bras Ter Intensiva. 2011; 23 (4): 394-409.

[18] Barkin RM, Michael EP, Joel SS, Suzanne ZB. Pediatric diphtheria and tetanus toxoids vaccine: Clinical and immunologic response when administered as primary series. The Journal of Pediatrics. 1985; 106: 779-81.

[19] Fair E, Murphy T, Golaz A, Wharton M. Philosophic objection to vaccination as a risk for tetanus among children younger than 15 years. Pediatrics. 2002; 109 (1): 1-3.

[20] Departemen Kesehatan RI. [Management of Tetanus in Children]. Penatalaksanaan Tetanus pada Anak [cited 2020 Jan 12]. Available from: https://www.academia.edu/Departemen+Kesehatan+RI.+Pena talaksanaan+Tetanus+pada+Anak.2008.

[21] Jozani Z, Ahmad S, Agha S. Tetanus in an unvaccinated child: A case report. Asian Pacific Journal of Tropical Disease. 2012; 2 (4): 335-6. 